\title{
Mechanical behavior of mullite-zirconia composites
}

\author{
F. Sahnoune ${ }^{1}$ and N. Saheb ${ }^{2}$ \\ ${ }^{1}$ Laboratoire de Physique et Chimie des Matériaux, Université de M'sila, 28000, Algeria \\ ${ }^{2}$ Department of Mechanical Engineering, King Fahd University of Petroleum \& Minerals, Dhahran, \\ 31261, Kingdom of Saudi Arabia
}

\begin{abstract}
In this work, mechanical properties of mullite-zirconia composites synthesised through reaction sintering of Algerian kaolin, $\alpha-\mathrm{Al}_{2} \mathrm{O}_{3}$, and $\mathrm{ZrO}_{2}$ were characterized. Phases present and their transformations were characterized using $\mathrm{x}$-ray diffraction. Hardness $\mathrm{H}$ and fracture toughness $\mathrm{K}_{\mathrm{IC}}$ were measured by Vickers indentation using a Zwick microhardness tester. The flexural strength was measured through three point bending test using an Instron Universal Testing Machine. It was found that the increase of $\mathrm{ZrO}_{2}$ content (from 0 to $32 \mathrm{wt} . \%$ ) decreased the microhardness of the composites from 14 to $10.8 \mathrm{GPa}$. However, the increase of $\mathrm{ZrO}_{2}$ content (from 0 to $24 \mathrm{wt} . \%$ ) increased the flexural strength of the composites from 142 to $390 \mathrm{MPa}$ then decreased it with further increase of $\mathrm{ZrO}_{2}$ content. Also, the fracture toughness increased from 1.8 to $2.9 \mathrm{MPa} \cdot \mathrm{m}^{1 / 2}$ with the increase of $\mathrm{ZrO}_{2}$ content from 0 to $32 \mathrm{wt} . \%$; and the rate of the increase decreased at higher fractions of $\mathrm{ZrO}_{2}$ content. The average linear coefficient of thermal expansion (within the range 50 to $1450^{\circ} \mathrm{C}$ ) for samples containing 0 and $16 \mathrm{wt} . \% \mathrm{ZrO}_{2}$ sintered at $1600^{\circ} \mathrm{C}$ for 2 hours was $4.7 \times 10^{-6} \mathrm{~K}^{-1}$ and $5.2 \times 10^{-6} \mathrm{~K}^{-1}$ respectively.
\end{abstract}

\section{Introduction}

Amongst structural engineering materials, mullite ceramics have many desirable properties, such as excellent high-temperature strength and creep resistance, good thermal and chemical stability, low thermal expansion coefficient, and low density $[1,2]$. However, monolithic mullite suffers from low values of bending strength and fracture toughness [3]. Zirconia has superior physical and mechanical properties including high hardness, wear resistance, elastic modulus, and high melting temperature [4]; and significant toughening can be obtained by incorporating zirconia particles in a mullite matrix. Different mechanisms are involved in the toughening: stress-induced transformation, microcraking, crack bowing and crack deflection.

Conventional indentation techniques are widely used for mechanical characterization of brittle materials. The advantages of the indentation method include the small size of the test specimen, the easy specimen preparation and the simplicity of the test $[5,6]$. It is possible to measure the hardness $(H)$ of the material from the residual impression. Also, analysis of the cracks emerging from the corners of the impression provides quantitative information on fracture toughness $\left(K_{\mathrm{IC}}\right)[5,7]$.

Many studies were devoted to the preparation and characterization of mullite-zirconia composites [8-12]. Garrido and co-workers [5] investigated the variation of the $H$ and $K_{\mathrm{IC}}$ mechanical parameters as a function of the microstructures of mullite-zirconia composites reaction-sintered from alumina-zircon mixtures from 1450 to $1600{ }^{\circ} \mathrm{C}$ under different firing conditions. They found that materials mainly composed by alumina-mullite-zirconia exhibited high hardness and fracture 
toughness. Rendtorff and co-workers [13] prepared mullite-zirconia-zircon composites from binary mixtures of zircon and mullite-zirconia powders and measured their mechanical and fracture properties. They concluded that while the flexural strength was related to the microstructure configuration, the other properties such as the young's modulus $E$, fracture toughness $K_{\text {IC }}$ presented clear linear correlation with the composites' composition. They reported that the elastic modulus decreased with the increase of the proportion of mullite-zirconia; and the composites with higher amounts of zirconia had higher fracture toughness. Khor el. al [14] prepared mullite-zirconia composites at a relatively low sintering temperature by reaction sintering of plasma spheroidized (PS) zircon-alumina powders in spark plasma sintering (SPS) system. They concluded that with optimized sintering parameters, the combination of PS and SPS was an effective material-processing route for preparing mullite/ $\mathrm{ZrO}_{2}$ composites with attractive mechanical properties from zircon/alumina mixture at a relatively low reaction sintering temperature.

In previous works we synthesised mullite through reaction sintering of Algerian kaolin and $\mathrm{Al}_{2} \mathrm{O}_{3}$ [14], and investigated the kinetics of mullite formation from Algerian kaolin [15]. Also, we investigated the effect of $\mathrm{MgO}$ [16] and $\mathrm{ZrO}_{2}$ [17] additions on the structure and sintering behaviour of mullite and mullite-zirconia composites. The objective of the present work is to investigate the mechanical behaviour of mullite-zirconia composites synthesised through reaction sintering of Algerian kaolin, $\alpha-\mathrm{Al}_{2} \mathrm{O}_{3}$, and $\mathrm{ZrO}_{2}$.

\section{Materials and Experimental Procedures}

Raw kaolin (DD3, from Guelma, Algeria) was used in this investigation, its chemical composition as determined by XRF is reported elsewhere [14-15]. $\alpha-\mathrm{Al}_{2} \mathrm{O}_{3}$ powder (MARTOXTD MDS-6) and zirconia containing $3 \mathrm{~mol} \% \mathrm{Y}_{2} \mathrm{O}_{3}$ (3Y-TZP, CRIGERAM) were added to kaolin to obtain 100/00, $92 / 08,84 / 16,76 / 24$ and $68 / 32$ mullite $/ \mathrm{ZrO}_{2}$ composites (by wt. \%), they are named KA00Z, KA08Z, KA16Z, KA24Z and KA32Z respectively. The powders were charged into cylindrical zirconia vials ( $250 \mathrm{ml}$ in volume) together with 15 zirconia balls $(10 \mathrm{~mm}$ in diameter). Water was added to the mixture at a ratio of $2: 1$. Ammonium polymethacylate $(1 \mathrm{wt} \%)$ was used as dispersant. Ammoniac was added to adjust the $\mathrm{pH}$ of the suspension at approximately 10.5. The ball-milling experiments were performed in a high-energy planetary ball mill (Fritsch P6) and were carried out at room temperature at a rotation speed of $250 \mathrm{rpm}$. The mixture was ball milled for 5 hours followed by attrition for 1 hour using $\mathrm{ZrO}_{2}$ balls (diameter of $1.2 \mathrm{~mm}$ ) at a speed of $1250 \mathrm{rpm}$. After attrition, the slurry was dried at $110^{\circ} \mathrm{C}$ and subsequently granulated by sieving. Samples containing $08,16,24,32$ wt. $\% \mathrm{ZrO}_{2}$ were prepared. A cold uniaxial press was used to shape bars $(25 \times 5 \times 2 \mathrm{~mm})$ and discs of 8 $\mathrm{mm}$ diameter and compact them at $75 \mathrm{MPa}$. The green samples were sintered between $1100^{\circ} \mathrm{C}$ and $1600^{\circ} \mathrm{C}$ for 2 hours, a heating rate of $10^{\circ} \mathrm{C} / \mathrm{min}$ was used. Phases present and their transformations were characterized using a Bruker x-ray diffractometer model D8 $\left(\mathrm{Cu} \mathrm{K}_{\alpha}\right.$ radiation and a Ni-filter) operated at $40 \mathrm{kV}, 40 \mathrm{~mA}$ with a scanning speed of $0.3 \%$ min and a step of 0.05 . Dynamic sintering of the samples was performed using a SETARAM Labsys thermal analyser. The shrinkage versus temperature was measured at a constant heating rate of $10^{\circ} \mathrm{C} / \mathrm{min}$. Vickers microhardness was measured using a Zwick microhardness tester model 3210; a load of $1000 \mathrm{~g}$ was used. The hardness of the samples was quantified using $\mathrm{H}_{\mathrm{V}}=1.8544 \mathrm{P} / \mathrm{d}^{2}$. The flexural strength of the samples was measured using the three point bending test in an Instron Universal Testing Machine, model 5500R. Experiments were carried out at a cross head speed of $0.5 \mathrm{~mm} / \mathrm{min}$ using bars having dimension $25 \times 5 \times 2 \mathrm{~mm}(\mathrm{LxWxH})$. Fracture toughness was determined using the indention micro-crack method $\left(\mathrm{K}_{\mathrm{IC}}=0.0937\left(\mathrm{H}_{\mathrm{V}} \mathrm{P} / 4 \mathrm{~L}\right)^{1 / 2}\right)$.

\section{Results and Discussion}

The microstructure of samples sintered for 2 hours at $1600^{\circ} \mathrm{C}$ was composed of mullite grains and $\mathrm{ZrO}_{2}$ particles. In samples with low $\mathrm{ZrO}_{2}$ content, mullite grains had whiskers' shape; however, the increase of $\mathrm{ZorO}_{2}$ content changed the morphology of mullite grains to near spherical shape. $\mathrm{ZrO}_{2}$ 
particles were uniformly distributed in the samples. More details on the microstructure and sintering behavior of the prepared mullite-zirconia composites were reported elsewhere [18]. The hardness, fracture toughness and flexural strength of the composites as a function of zirconia content is shown in figure 1. Vicker's hardness of the samples was measured using a load of $1000 \mathrm{~g}$ which was optimized using different loads ranging from $100 \mathrm{~g}$ to $2000 \mathrm{~g}$. It was found that with the increase of the load, the hardness decreased and remained almost unchanged at loads greater than $800 \mathrm{~g}$. The value of the hardness of each sample was the average of at least six measurements. Even though the samples were carefully prepared, the standard deviation was around $10 \%$. The increase of zirconia content from 0 to $32 \mathrm{wt} . \%$ decreased the hardness from 14 to $10.8 \mathrm{GPa}$ respectively as shown in figure 1(a).

Figure 1(b) shows the flexural strength of the samples as a function of $\mathrm{ZrO}_{2}$ content. The increase of $\mathrm{ZrO}_{2}$ content from 0 to $24 \mathrm{wt} . \%$ increased the flexural strength from 142 to $390 \mathrm{MPa}$ then decreased it with further increase of $\mathrm{ZrO}_{2}$ content. This is due to the fact that for samples containing less that 24 wt. $\% \mathrm{ZrO}_{2}$, the increase of $\mathrm{ZrO}_{2}$ content increases the fraction of $\mathrm{ZrO}_{2}$ changing from tetragonal to monoclinic as it is shown in figure 2 and explained below. It is known that the change from tetragonal to monoclinic generates microcracks that restrict dislocations' movement when the material is stressed. From the other side, when the fraction of monoclinic phase exceeds a specific value it will negatively affect the flexural strength as a result of the formation of macro-cracks which facilitates dislocations' movement. However, it is believed that at high temperatures the flexural strength will continue to increase with the increase of $\mathrm{ZrO}_{2}$ content up to $32 \mathrm{wt} . \%$ because heating will be accompanied with expansion which acts opposite to the polymorphic change from tetragonal to monoclinic.

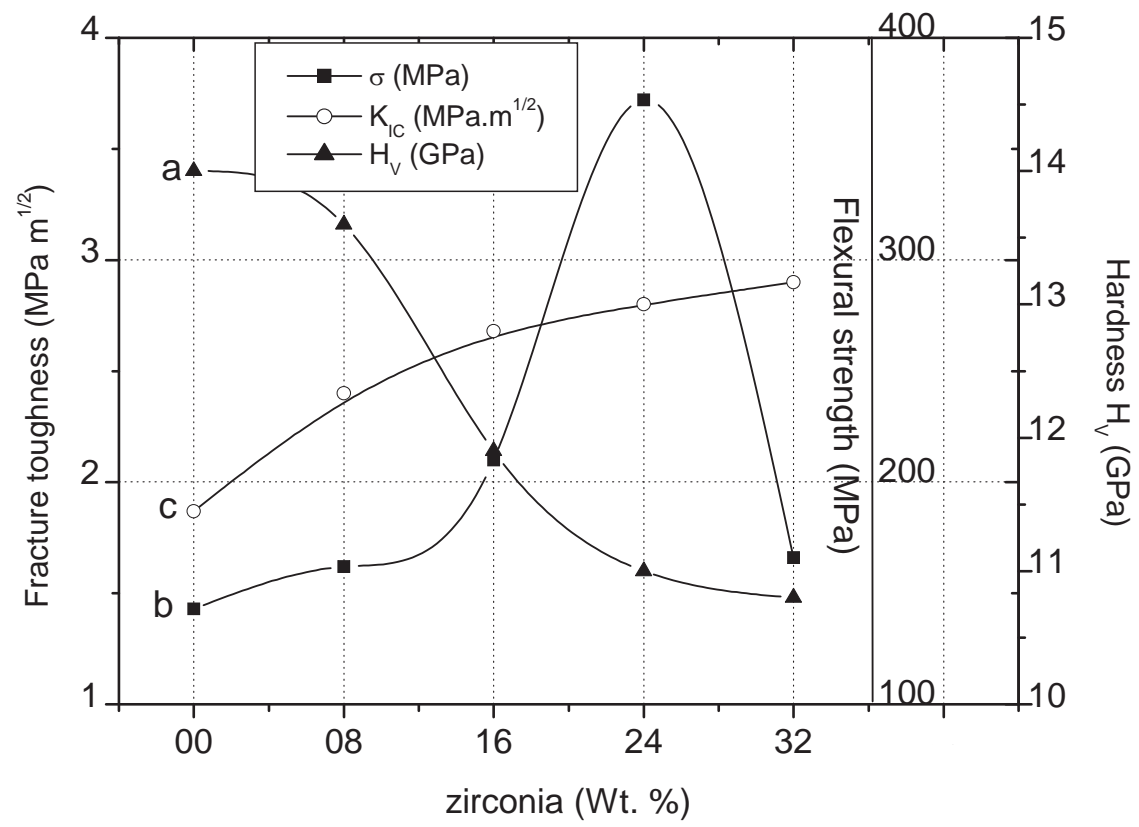

Figure 1: Vicker's hardness, fracture toughness and flexural strength as a function of zirconia content

Figure 1(c) shows the change of fracture toughness as a function of $\mathrm{ZrO}_{2}$ content. As it clearly seen, the fracture toughness increased from 1.8 to $2.9 \mathrm{MPa} . \mathrm{m}^{1 / 2}$ with the increase of $\mathrm{ZrO}_{2}$ content from 0 to $32 \mathrm{wt} . \%$; and the rate of the increase decreased at higher fractions of $\mathrm{ZrO}_{2}$ content. 
Quantitative phase analysis was performed following the Rietveld method using the software package X'Pert Highscore Plus. The retained tetragonal fraction of $\mathrm{ZrO}_{2}$ was obtained from the ratio of intensity of the (111) tetragonal peak to the sum of the intensities of the (111) and ( 111$)$ monoclinic and (111) tetragonal peaks [19]. Analysis of qualitative and quantitative XRD data showed that the monoclinic $\mathrm{ZrO}_{2}$ starts to form at $1400^{\circ} \mathrm{C}$ and the fraction increased with the increase of temperature up to $1600^{\circ} \mathrm{C}$. In the composite containing 16 wt. $\% \mathrm{ZrO}_{2}$, the ratio of tetragonal zirconia transformed to monoclinic zirconia is relatively small and did not exceed $18 \%$. This ratio has an important role in the improvement of the flexural strength and fracture toughness as discussed above. However, in the composite containing $32 \mathrm{wt} . \% \mathrm{ZrO}_{2}$ around $75 \%$ of the tetragonal structure changed to monoclinic structure which is enough to generate macro-cracks that negatively affect the mechanical performance of the material.
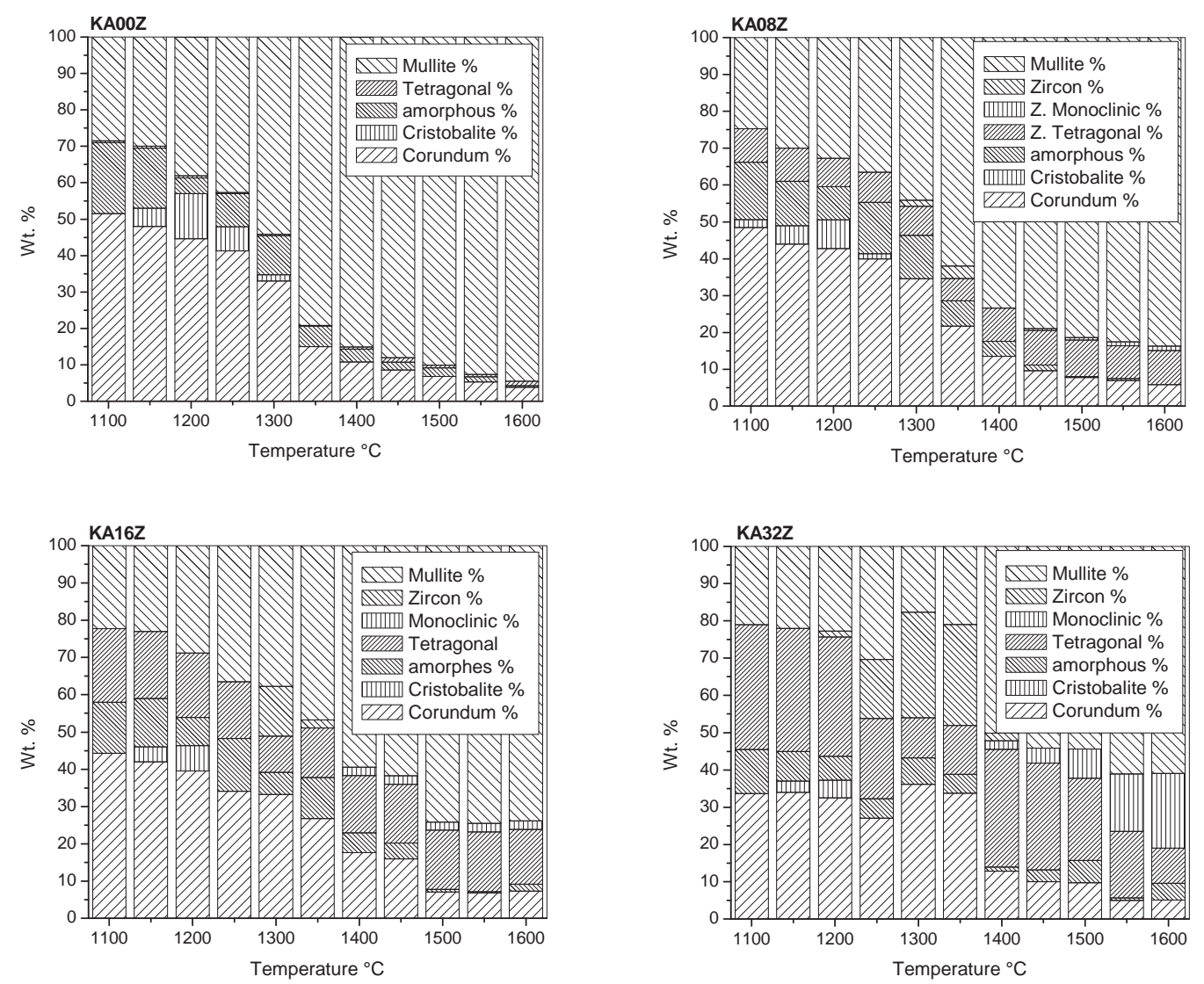

Figure 2: Weight fraction of crystalline and none crystalline phases present in samples containing $0,8,16$, and $32 \%$ of $\mathrm{ZrO}_{2}$ sintered at different temperatures for 2 hours.

The linear coefficient of thermal expansion (within the range 50 to $1450^{\circ} \mathrm{C}$ ) for samples containing 0,16 and 32 wt. $\% \mathrm{ZrO}_{2}$ sintered at $1600^{\circ} \mathrm{C}$ for 2 hours is shown in figure 3 . The average of the linear coefficient of thermal expansion was $4.7 \times 10^{-6} \mathrm{~K}^{-1}$ for sample containing $0 \mathrm{wt} . \% \mathrm{ZrO}_{2}$ and 5.2 $\mathrm{x} 10^{-6} \mathrm{~K}^{-1}$ for sample containing $16 \mathrm{wt} . \% \mathrm{ZrO}_{2}$. This is a good result compared to published works where the average of the linear coefficient of thermal expansion for the same temperature range was between $4.5 \times 10^{-6} \mathrm{~K}^{-1}$ and $6.3 \times 10^{-6} \mathrm{~K}^{-1}$ for unreinforced mullite $[20,21]$ and $5.2 \times 10^{-6} \mathrm{~K}^{-1}$ and $7.2 \mathrm{x}$ $10^{-6} \mathrm{~K}^{-1}$ for mullite reinforced with $\mathrm{ZrO}_{2}$ [22]. For zirconia content higher than 16 wt.\% during 
heating zirconia will change from monoclinic to tetragonal and the inverse is true during cooling; figure 3 shows that the temperature of change is $480^{\circ} \mathrm{C}$ for cooling and $920^{\circ} \mathrm{C}$ for heating. The coefficient of thermal expansion is very important for applications at high temperatures because the lower the coefficient, the longer life time of the material. Pure mullite has very low linear coefficient of thermal expansion, but compared to other materials when it is applied under compressive stress its resistance decreases with the increase of temperature. Therefore, even the addition of zirconia led to a small increase in the coefficient of thermal expansion the improvement in mechanical properties was significant.

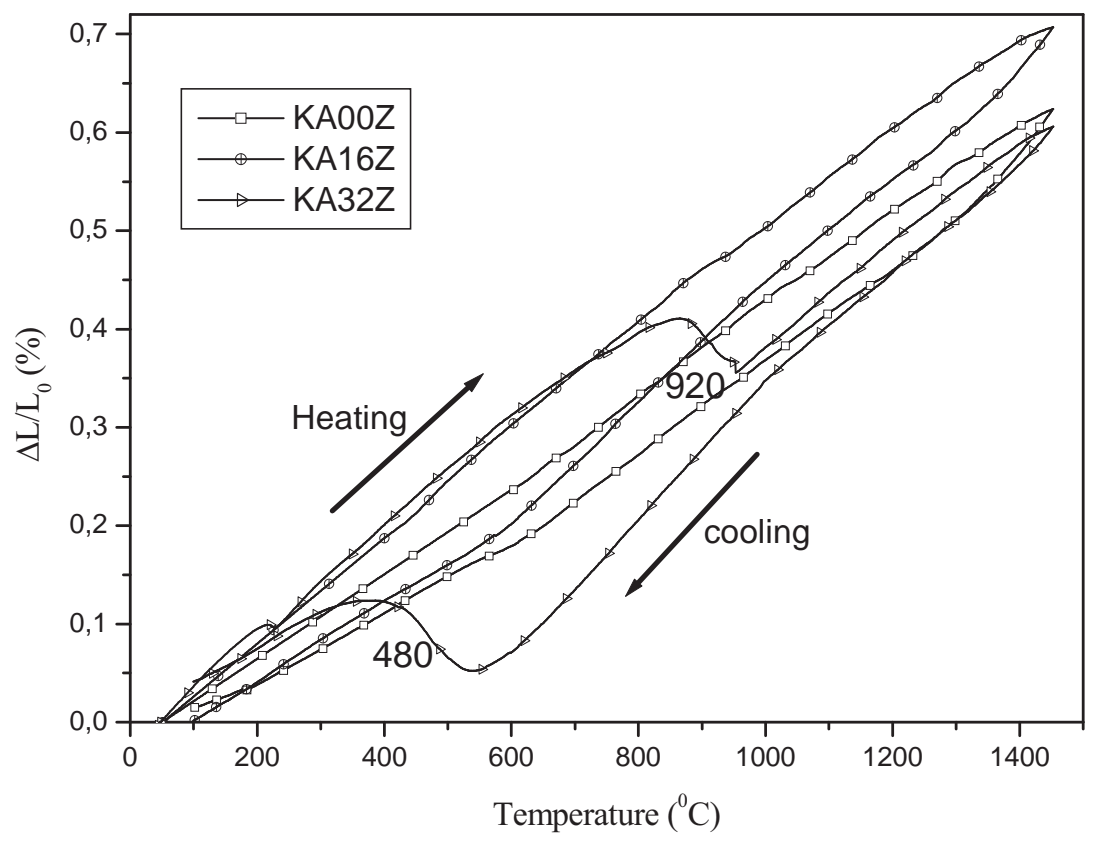

Figure 3: Thermal expansion curves of KA00Z, KA16Z and KA32Z (heating and cooling rate $\left(20^{\circ} \mathrm{C} / \mathrm{min}\right)$

\section{Conclusion}

Mechanical properties of mullite-zirconia composites synthesised through reaction sintering of Algerian kaolin, $\alpha-\mathrm{Al}_{2} \mathrm{O}_{3}$, and $\mathrm{ZrO}_{2}$ were characterized. It was found that the increase of $\mathrm{ZrO}_{2}$ content (from 0 to $32 \mathrm{wt} . \%$ ) decreased the microhardness of the composites from 14 to $10.8 \mathrm{GPa}$. However, the increase of $\mathrm{ZrO}_{2}$ content (from 0 to 24wt.\%) increased the flexural strength of the composites from 142 to $390 \mathrm{MPa}$ then decreased it with further increase of $\mathrm{ZrO}_{2}$ content. The fracture toughness increased from 1.8 to $2.9 \mathrm{MPa} . \mathrm{m}^{1 / 2}$ with the increase of $\mathrm{ZrO}_{2}$ content from 0 to 32 wt.\%; and the rate of the increase decreased at higher fractions of $\mathrm{ZrO}_{2}$ content. The average linear coefficient of thermal expansion (within the range 50 to $1450^{\circ} \mathrm{C}$ ) for samples containing 0 and 16 wt. $\% \mathrm{ZrO}_{2}$ sintered at $1600^{\circ} \mathrm{C}$ for 2 hours was between $4.7 \times 10^{-6} \mathrm{~K}^{-1}$ and $5.2 \times 10^{-6} \mathrm{~K}^{-1}$ respectively.

Acknowledgements: The authors are grateful to the technical and financial support from Laboratoire de Physique et Chimie des Matériaux, Université de M'sila, Algeria, and the Department of Special Ceramics, ENSM, France. Also, the corresponding author would like to acknowledge the financial support from King Fahd University of Petroleum and Minerals, Kingdom of Saudi Arabia. 


\section{References}

1. Cem Öztürk, Yahya Kemal Tür, J. Eur. Ceram. Soc. 27, 1463 (2007)

2. J. Meng, S. Cai, Z. Yang, Q. Yuan and Y. Chen, J. Eur. Ceram. Soc. 18, 1107 (1998)

3. H.R. Rezaie, W.M. Rainforth, W.E. Lee, J. Eur. Ceram. Soc. 19, 1177 (1999)

4. R.H. Hannink, P.M. Kelly, B.C. Muddle, J. Am. Ceram. Soc. 83, 46 (2000)

5. L.B. Garrido, E.F. Aglietti, L. Martorello, M.A. Camerucci, A.L. Cavalieri, Mater. Sci. Eng. A 419, 290 (2006)

6. J. Gong, Ceram. Int. 28, 767 (2002)

7. K.M. Liang, G. Orange, G. Fantozzi, J. Mater. Sci. 25, 207 (1990)

8. Kaberi Das, G. Banerjee, J. Eur. Ceram. Soc. 20, 153 (2000)

9. V. Yaroshenko and D.S. Wilkinson, J. Am. Ceram. Soc. 84, 850 (2001)

10. N. Claussen and J. Jahn, J. Am. Ceram. Soc. 63, 228 (1980)

11. T. Koyama, S. Hayashi, A. Yasumori, K. Okada, M. Schmucker and H. Schneider, J. Eur. Ceram. Soc. 16, 231 (1996)

12. P. Descamps, S. Sakaguchi, M. Poorteman and F. Cambier, J. Am. Ceram. Soc. 74, 2476 (1991)

13. N.M. Rendtorff L.B. Garrido, E.F. Aglietti, Ceram. Iter. 36, 781 (2010)

14. K.A. Khor, L.G. Yu, Y. Li, Z.L. Dong, Z.A. Munir, Mater. Sci. Eng. A 339, 286, (2003)

15. F. Sahnoune, M. Chegaar, N. Saheb, P. Goeuriot, F. Valdivieso, App. Clay Sci. 38, 304 (2008)

16. F. Sahnoune, M. Chegaar, N. Saheb, P. Gueuriot, F. Valdivieso, Adv. App. Ceram. 107, 9 (2008)

17. M. Heraiz, A. Merrouche, N. Saheb, Adv. App. Ceram. 105, 285 (2006)

18. F. Sahnoune, N. Saheb, M. Chegaar, P. Goeuriot, Materials Science Forum 638-642, 979 (2010)

19. R.C. Garvie, P.S. Nicholson, J. Am. Ceram. Soc., 55, 303 (1972)

20. G. Brunauer, F. Frey, H. Boysen, H. Schneider, J. Europ. Ceram. Soc., 21, 2503 (2001)

21. H. Schneider, E. Eberhard, J. Am. Ceram. Soc., 73, 2073 (1990)

22. J. Barin, O. Knacke, Thermochemical Properties of Inorganic Substances. (Springer, Berlin, 1973) 